Article

\title{
Impact of Culture pH Regulation on Biohydrogen Production using Suspended and Immobilized Microbial Cells
}

\author{
Joelle Penniston and Evariste Bosco Gueguim Kana * \\ School of Life Sciences, University of KwaZulu-Natal, Pietermaritzburg 3209, South Africa; \\ pennistonj@gmail.com \\ * Correspondence: kanag@ukzn.ac.za
}

\begin{abstract}
The effect of $\mathrm{pH}$ regulation on biohydrogen production was studied using suspended and immobilized mixed cultures. Four sets of experiments were conducted using suspended cells under regulated $\mathrm{pH}$ (Sus_R) and non-regulated $\mathrm{pH}$ conditions (Sus_N) as well as alginateimmobilized cells under $\mathrm{pH}$ regulated $\left(\mathrm{Imm} \_\mathrm{R}\right)$ and non- $\mathrm{pH}$ regulated conditions (Imm_N). Sus_R showed a peak hydrogen fraction of $44 \%$ and complete glucose degradation, compared to Sus_N with a peak hydrogen fraction of $36 \%$ and a glucose degradation of $37 \%$. Imm_R experiments showed a peak biohydrogen fraction of $35 \%$, while the peak hydrogen fraction observed with Imm_N was $22 \%$. The highest hydrogen fraction was observed using suspended cells under regulated $\mathrm{pH}$ conditions. A $100 \%$ glucose degradation was observed in both $\mathrm{pH}$ regulated and non-regulated processes using immobilized cells. The rate of $\mathrm{pH}$ change was slower for immobilized cells compared to suspended cells suggesting a better buffering capacity under non $\mathrm{pH}$ regulated conditions. The study showed that biohydrogen production with suspended cells in a non-regulated $\mathrm{pH}$ environment resulted in early termination of the process and lower productivity.
\end{abstract}

Keywords: pH regulation; biohydrogen; suspended; immobilized; productivity 


\section{Introduction}

A large fraction of the global energy needs currently rely on fossil fuels. Furthermore, the constantly increasing human population has led to an upsurge in the global energy demand which may eventually result in the complete depletion of fossil fuel reserves in the near future [1]. In addition, fossil fuels are expensive and raise pollution concerns as their combustion results in the release of various pollutants including greenhouse gases, thereby, raising concerns for global climate change $[2,3]$. These concerns have fueled the need to seek for alternative energy sources that are sustainable, renewable and non-polluting. Biohydrogen has been identified as a propitious alternative owing to its high energy content as well as renewable and environmentally friendly qualities [4-6]. Furthermore, fermentative biohydrogen production offers the advantage of being less energy intensive and can be operated at ambient temperature, thus making it a feasible option for large scale hydrogen production [7].

Hydrogen production through the dark fermentation technology is the most commonly used production process [8]. It refers to the process of converting organic materials to biohydrogen through a cascade of biochemical reactions by fermentative microorganisms in the absence of oxygen $[1,8]$ and has the dual advantage of being a non-polluting biofuel as well as an effective method for waste water treatment [1]. Although fermentative biohydrogen is a promising energy source, there is a need for in-depth knowledge of the impact of key physico-chemical parameters such as $\mathrm{pH}$. in order for its production to become commercially viable. Extensive knowledge on the limitations of flask experimental based models for process development are required to overcome the challenges associated with biohydrogen production such as low yield and high production costs [1,9]. 
The medium $\mathrm{pH}$ has been reported as one of the major parameters affecting biohydrogen production. Bacteria generally respond to changes in internal and external $\mathrm{pH}$ by shifting their activity associated with various metabolic processes such as proton translocation, substrate degradation $[10,11]$. Variations in $\mathrm{pH}$ can disrupt molecular structures and affect intracellular and extracellular reactions. For example, at extreme $\mathrm{pH}$ proteins are denatured and the DNA double-helix strand is destabilized. Since many microorganisms involved in anaerobic fermentation produce acids as metabolic by-products [12], there is a constant drift in the linearity of the $\mathrm{pH}$ within the production system. This drift leads to metabolic shift in hydrogen-producing bacteria which could result in the inhibition of product formation. Reported flask scale experimental studies of biohydrogen without $\mathrm{pH}$ control abound in the public domain. A study by Liu et al [13] reported an initial $\mathrm{pH}$ of 7.0 without $\mathrm{pH}$ regulation for the production of biohydrogen using a combination of dark and photo-fermentative batch culture. In the same vein, various studies on biohydrogen production at flask scale only stated the initial $\mathrm{pH}$ value without indication of further regulation during the fermentation process [3, 14]. To a great extent, the sensitivity of metabolic shift under $\mathrm{pH}$ drift poses significant challenges on experimental models with the $\mathrm{pH}$ parameter among the input variables. This is evidenced in the assessment of the initial $\mathrm{pH}$ and glucose concentration interaction on biohydrogen production kinetics [15].

The use of immobilized cell systems in bioprocess development has several advantages as compared to suspended cells systems. These include better handling and the repeated use of cells as well as improved solid to liquid separation efficiency [16]. Immobilized cell culture systems for the continuous production of hydrogen using pure and mixed cultures have been reported [16-18]. However, there is a dearth of knowledge in public domain on the potential of cell immobilization as a $\mathrm{pH}$ buffering matrix for anaerobic biofuel fermentation processes. 
Various studies for biohydrogen production have been carried out using shake flask bioreactors. These flasks are advantageous in the fact that they allow the operation of simultaneous experiments [19]. In spite of their widespread acceptance, shake flasks have significant limitations. For example, conventional flask shakers shake according to linear reciprocating movement. This concept is well established and the associated mixing deficiencies are well understood [20]. Some of the challenges include; the dissimilarities in oxygen transfer due to differences in the agitation systems of shake flask and pilot scale fermenters as well as inconsistencies in aeration, mixing efficiency, temperature and $\mathrm{pH}$ regulation systems [21]. The ramifications of these deficiencies include the impact on data validity for process scale up. The non-linearity associated with unregulated $\mathrm{pH}$ poses many difficulties for bioprocessing and has been linked to reduced bioprocess yields. Ironically, most reported biohydrogen flask scale data generated under non-pH regulated culture systems form the basis of process scale up in $\mathrm{pH}$ regulated pilot size bioreactor.

This study therefore aims at investigating the effects of regulated and non-regulated $\mathrm{pH}$ on hydrogen production in shake flask bioreactors using suspended and immobilized cell systems.

\section{Material and methods}

\subsection{Inoculum development}

The hydrogen-producing mixed consortium used in this study was obtained from the anaerobic digested sludge collected from Darvill wastewater treatment plant, Pietermaritzburg, South Africa. The collected sludge was immediately transferred to the laboratory and stored at $4{ }^{\circ} \mathrm{C}$. A combination of alkaline and heat treatment was applied as previously described by Faloye et al [22]. This pre-treatment step was included to inactivate methanogens and promote the survival of endospore-forming hydrogen producers. 


\subsection{Fermentation process in batch reactors using suspended cells}

Two sets of fermentation processes were carried out in duplicate in $250 \mathrm{ml}$ conical Erlenmeyer flask bioreactors under both regulated and non-regulated $\mathrm{pH}$ conditions. The reactors were fed with glucose as a substrate at a concentration of $10 \mathrm{~g} / \mathrm{L}$ and supplemented with inorganic salts at the following concentration $(\mathrm{g} / \mathrm{L}): 1.5 \mathrm{KH}_{2} \mathrm{PO}_{4}, 1.5 \mathrm{~K}_{2} \mathrm{HPO}_{4}, 2.0\left(\mathrm{NH}_{4}\right)_{2} \mathrm{SO}_{4}, 0.1 \mathrm{FeCl}, 0.1$ $\mathrm{CaCl} \cdot 2 \mathrm{H}_{2} \mathrm{O}, 0.05 \mathrm{ZnSO}_{4}, 0.01 \mathrm{Na} 2 \mathrm{MoO}_{4}, 0.08 \mathrm{MnCl} \cdot 6 \mathrm{H}_{2} \mathrm{O}$. Each reactor was inoculated with $25 \mathrm{ml}$ of pre-treated sludge and made up to a total working volume of $250 \mathrm{ml}$ with the inorganic salts media. Anaerobic conditions were induced by purging the reactors with nitrogen gas for 5 minutes. The initial $\mathrm{pH}$ was adjusted to 6.5 with $0.1 \mathrm{M} \mathrm{NaOH}$ or $0.1 \mathrm{M} \mathrm{HCl}$. Fermentation experiments were carried out in duplicate under non-regulated $\mathrm{pH}$ conditions in a shaking waterbath with operational setpoints of $37.5^{\circ} \mathrm{C}$ and $180 \mathrm{rpm}$ for temperature and agitation, respectively. Control experiments under regulated $\mathrm{pH}$ at 6.5 were run in parallel. The $\mathrm{pH}$ control systems consisted of an Alpha 190 automatic controller connected to a peristaltic dosage pump dispensing an amount of $1 \mathrm{M} \mathrm{NaOH}$ whenever the $\mathrm{pH}$ drift below the setpoint value. Thus a closed feedback control loop was implemented as shown in figure 1. All experiments were carried out in replicates for a process time of 48 hours. 


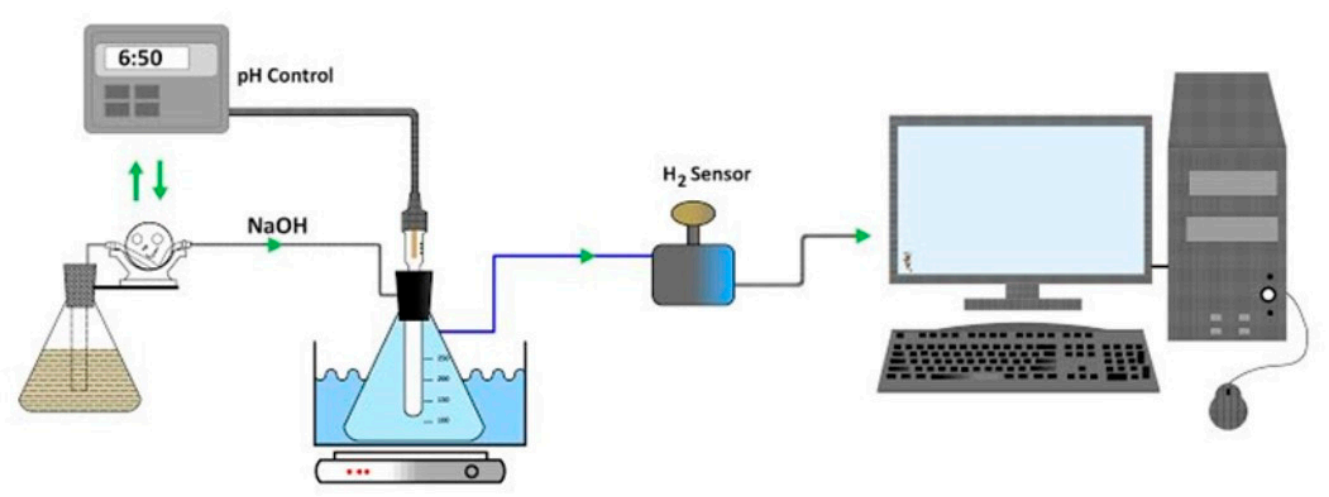

Figure 1: Schematic diagram of experimental set up with $\mathrm{pH}$ control loop and datalogging system

\subsection{Fermentation process in batch reactors using immobilized cells}

Two sets of immobilized culture experiments were carried out under regulated and nonregulated $\mathrm{pH}$ conditions. The mixed microbial cells were immobilized by entrapment into the sodium alginate beads. Sodium alginate (Sigma) was dissolved in distilled water and autoclaved for 15 minutes to form a final alginate concentration of $3 \%$. The sodium alginate solution when cooled was mixed with an equal volume of the pre-treated anaerobic sludge to a form a 50:50 alginate to sludge ratio. $2 \%$ granular activated carbon was added to the mixture to increase bead porosity. The alginate/sludge mixture was then transferred through a peristaltic pump into a $0.2 \mathrm{M} \mathrm{CaCl}$ solution to form beads of approximately $0.3 \mathrm{~mm}$ in diameter.

Each reactor was inoculated with a $20 \% \mathrm{v} / \mathrm{v}$ concentration of alginate-sludge beads and made up to a total working volume of $250 \mathrm{ml}$ with the inorganic salts solution containing $10 \mathrm{~g} / \mathrm{L}$ glucose. The initial $\mathrm{pH}$ was adjusted to $\mathrm{pH}$ 6.5. Regulated $\mathrm{pH}$ experiments were set up as 
described above in figure 1. All experiments were carried out in duplicate in a waterbath shaker at a constant temperature of $37.5^{\circ} \mathrm{C}$ and an agitation of $180 \mathrm{rpm}$ for a process time of 48 hours.

\subsection{Process monitoring and analysis}

Changes in the biohydrogen fraction of the evolving gas were measured continuously using the F-Lab Biogas Software previously described by Gueguim Kana et al [23] with a sampling frequency of 1 minute and equipped with a BCP-H2 sensor (Blue-Sens, Germany). The sensor has a measuring range of $0-100 \%$ hydrogen and employs the thermal conductivity measurement principle. Effluent samples were taken from the reactor at lag and exponential phase, at optimal hydrogen production as well as at decline phase and the residual glucose concentration was measured using a glucose analyzer (Model 200 Select, YSI, USA). For non $\mathrm{pH}$ regulated experiments, the $\mathrm{pH}$ was continuously monitored at 1 minute interval using a $\mathrm{pH}$ probe (Crison, South Africa) connected to a programmed Arduino Microcontroller data-logger, and the Parallax spreadsheet was used for database storage.

\subsection{Microbial analysis}

The morphology of the hydrogen-producing organisms was analyzed using phase contrast and Scanning Electron Microscopy (SEM) for the suspended and immobilized cell culture systems, respectively. For phase contrast analysis $50 \mu \mathrm{l}$ of effluent was sampled at peak hydrogen production and mixed with 3\% gluteraldehyde and viewed. For SEM analysis alginate beads were sampled at peak hydrogen production and fixed with 3\% gluteraldehyde for 3 hours. The fixed samples were then dehydrated stepwise in a graded series of ethanol solutions, ranging from $0-100 \%$ ethanol, and critical-point dried using carbon dioxide. Finally, the dried beads were sputter coated with gold prior to SEM observation. 


\section{Results and discussion}

\subsection{Impact of culture medium $\mathrm{pH}$ on hydrogen production in dark fermentation using suspended mixed cultures}

\subsubsection{Biohydrogen production under non-regulated pH conditions in suspended cell cultures}

Figure 2 illustrates the biohydrogen and $\mathrm{pH}$ evolution under non-regulated $\mathrm{pH}$ conditions using suspended cells. A slow decline in $\mathrm{pH}$ from an initial value of 6.5 was observed in the first 5 hours of fermentation, followed by a rapid drop in $\mathrm{pH}$ with a simultaneous increase in biohydrogen fraction. Thus, the lag phase lasted 5 hours. The short lag phase observed in this culture system may be accounted for by the high accessibility of the cells to glucose substrate as it is a monosaccharide that is easily broken down by microorganisms. Previous studies have indicated that the duration of the lag phase may be influenced by medium $\mathrm{pH}$. For instance, O'Sullivan and Condon [24] observed that the lag phase was shorter under alkaline pH and mesophilic temperatures compared to acidic and thermophilic temperature conditions. The hydrogen fraction increased exponentially to a peak value of $36 \%$ after 12 hours, corresponding to a $\mathrm{pH}$ of 4.67 (Figure 2). Biohydrogen production predominantly occurs in the acidification stage where carbohydrates are rapidly converted to hydrogen by fermentative bacteria. This results in accumulation of acid by-products such as volatile fatty acids, causing a drop in the $\mathrm{pH}[25]$ and ultimately leading to the termination of hydrogen production. This drop in $\mathrm{pH}$ can also lead to complete microbial inactivation depending on the magnitude of the decrease [26]. 


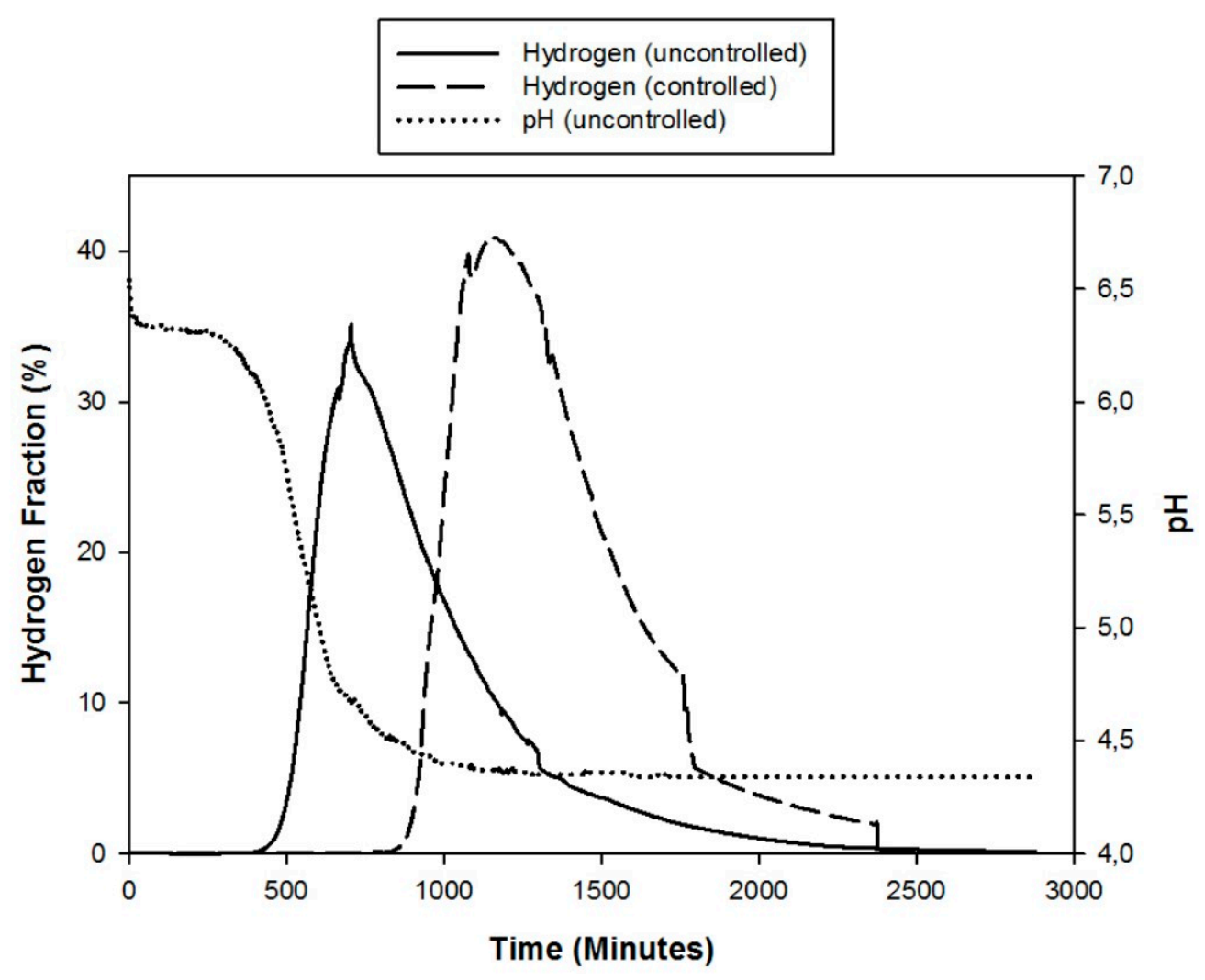

Figure 2: A comparative evolution of hydrogen fraction and $\mathrm{pH}$ under regulated (pH 6.5) and non-regulated $\mathrm{pH}$ conditions using suspended cells

It has been found that a high concentration of undissociated acids increases the ionic strength of the solution, switching the metabolic pathway from hydrogen production to solvent production. Although the extent to which $\mathrm{pH}$ is able to affect the metabolic pathway of the hydrogen-producing community may vary depending on the inoculum as well as the characteristics of the substrate used [27,28]. These acids diffuse across the cell membrane and rapidly dissociate because of a higher intracellular $\mathrm{pH}$, resulting in the acidification of the cytoplasm by the release of $\mathrm{H}^{+}$ions [29]. This causes an increase in the energy required to maintain cell $\mathrm{pH}$ homeostasis and thus the energy of the cell is redirected toward maintaining 
neutrality. The movement of undissociated acids across the cell membrane may also disrupt the proton motive force. Disruption of the proton motive force largely affects nutrient transport into the cell as well as crucial enzymatic reactions and may also lead to DNA alteration and microbial inactivation [31].

The decline in hydrogen production observed below pH 4.67 (Figure 2) might have been triggered by the transition of the fermentation system from acidogenesis to solventogenesis, a phenomenon which typically occurs at $\mathrm{pH} 4.5$. This metabolic shift results in the production of more neutral by-products such as acetate or alcohols as it can be noticed that the $\mathrm{pH}$ of the fermentation system continues to decrease throughout the fermentation process. However, after optimum hydrogen fraction (36\%) was reached, the rate of $\mathrm{pH}$ change became slower. The duration of the peak hydrogen production was relatively short (3 minutes) with a prevailing $\mathrm{pH} 4.67$, which may be due to the rapid drift in medium $\mathrm{pH}$ to inhibitory levels under nonregulated $\mathrm{pH}$ conditions. Khanal et al [14] reported that with an initial $\mathrm{pH}$ of 6.5 , the fermentation $\mathrm{pH}$ dropped more rapidly and the hydrogen production phase was shorter. It was suggested that the rapid hydrogen production observed at this $\mathrm{pH}$ was accompanied by rapid acid-production to inhibitory levels, thus reducing the buffering capacity of the system. The onset of solventogenesis can account for the short production phase observed in the nonregulated $\mathrm{pH}$ study. This metabolic shift occurred as a result of volatile fatty acid and hydrogen accumulation within the batch system. Thus the removal of excess hydrogen as well as the regulation of $\mathrm{pH}$ at an optimal setpoint can be used to sustain hydrogen production [31]. A possible relationship between the change in fermentation $\mathrm{pH}$ as well as evolution of the hydrogen fraction was also investigated. A strong correlation was observed between the hydrogen evolution trend and $\mathrm{pH}$ at exponential production, peak production as well as the decline phase with a correlation coefficient of $0.93,1$ and 0.93 , respectively. 
3.1.2 Substrate degradation profile under non-regulated $p H$ condition in suspended cells culture.

Substrate degradation analyses revealed that the glucose concentration decreased from an initial concentration of $10 \mathrm{~g} / \mathrm{L}$ to $9.9 \mathrm{~g} / \mathrm{L}$ after 7 hours of fermentation, corresponding to the early exponential phase. A residual glucose concentration of $7.3 \mathrm{~g} / \mathrm{L}$ was observed at the peak production corresponding to hydrogen fraction of $36 \%$ with a prevailing $\mathrm{pH}$ value of 4.67 , then substrate degradation slowed down significantly to a final concentration of $6.3 \mathrm{~g} / \mathrm{L}$ at the end of the fermentation process. The overall substrate consumption, therefore, was $37 \%$. This suggests that the decrease in hydrogen production may be due to acid inhibition rather than substrate depletion and that $\mathrm{pH} 4.67$ may be the minimum threshold for hydrogen production and substrate degradation. These findings are similar to a study by Lay [32] which suggested that hydrogen production may proceed at an optimum rate when the fermentation $\mathrm{pH}$ is maintained at a setpoint of 5.2, but decline if the $\mathrm{pH}$ is below 4.7. Due to accumulation of volatile fatty acids during glucose fermentation, the $\mathrm{pH}$ generally decreased and it has been reported that high levels of dissociated VFAs present in the fermentation media increased the ionic strength of the solution, leading to cell lysis [33]. Butyrate is well known as one of the major VFA constituents in fermentative hydrogen production. In a study by Zheng and Yu [34] investigating the effects of butyrate on hydrogen production, glucose degradation was found to be high $(98 \%)$ at butyrate concentrations ranging from $0-12.4 \mathrm{~g} / \mathrm{L}$ of added butyrate. However, glucose degradation was reduced to only $36 \%$ at a concentration of $25.08 \mathrm{~g} / \mathrm{L}$ of added butyrate.

\subsubsection{Biohydrogen production and substrate degradation profiles under $p H$ regulated} conditions in suspended cells culture.

The hydrogen evolution trend under $\mathrm{pH}$ controlled conditions using suspended cells is shown in Figure 3. A lag phase of 5 hours was observed, followed with an exponential increase in the 
biohydrogen fraction to a peak hydrogen fraction of $44 \%$ at 21 hours. This peak hydrogen production phase lasted up to 45 minutes, compared to 3 minutes observed in non-regulated $\mathrm{pH}$ conditions. Peak production was followed by a gradual decline in hydrogen production as the carbon source gradually depleted. These results suggested that $\mathrm{pH}$ regulation with suspended cell cultures increased the biohydrogen fraction and the process productivity. Glucose analysis showed that the concentration of glucose decreased from an initial value of $10 \mathrm{~g} / \mathrm{L}$ to $7 \mathrm{~g} / \mathrm{L}$ at early exponential phase. A residual glucose concentration of $4.4 \mathrm{~g} / \mathrm{L}$ was measured at optimum hydrogen production at 21 hours which decreased to $0 \mathrm{~g} / \mathrm{L}$ at the 24 hours. These results showed that $\mathrm{pH}$ regulation enhances substrate degradation. Fang and Liu [35] showed that continuous control of $\mathrm{pH}$ within a range of $\mathrm{pH} 5.5-7.0$ resulted in complete substrate degradation while the control of $\mathrm{pH}$ below a setpoint of 5.5 resulted in the partial degradation of glucose.

\subsection{Impact of culture medium $\mathrm{pH}$ on hydrogen production in dark fermentation using immobilized mixed cultures.}

\subsubsection{Biohydrogen production under non-regulated $p H$ conditions with immobilized cells culture}

Figure 3 represents the hydrogen fraction and corresponding $\mathrm{pH}$ evolution using a mixed microbial population immobilized in sodium-alginate beads under non-regulated and regulated $\mathrm{pH}$ conditions. The lag phase lasted 5 hours, throughout which the $\mathrm{pH}$ remained relatively stable at 6.5. A steady drop in $\mathrm{pH}$ was observed after the $5^{\text {th }}$ hour. This decrease in $\mathrm{pH}$ was accompanied by a concomitant increase in biohydrogen fraction. This pattern of sharp decrease in $\mathrm{pH}$ during the exponential phase of hydrogen production was observed in all four culture systems. The hydrogen fraction increased exponentially up to a peak fraction of $21 \%$ after 16 
hours, corresponding to a $\mathrm{pH}$ of 4.54. This peak was maintained for 1 hour during which the $\mathrm{pH}$ remained fairly stable at 4.5. Presumably, cell immobilization increased the buffering capacity of the system, therefore, sustaining a longer duration of hydrogen production at peak fraction.

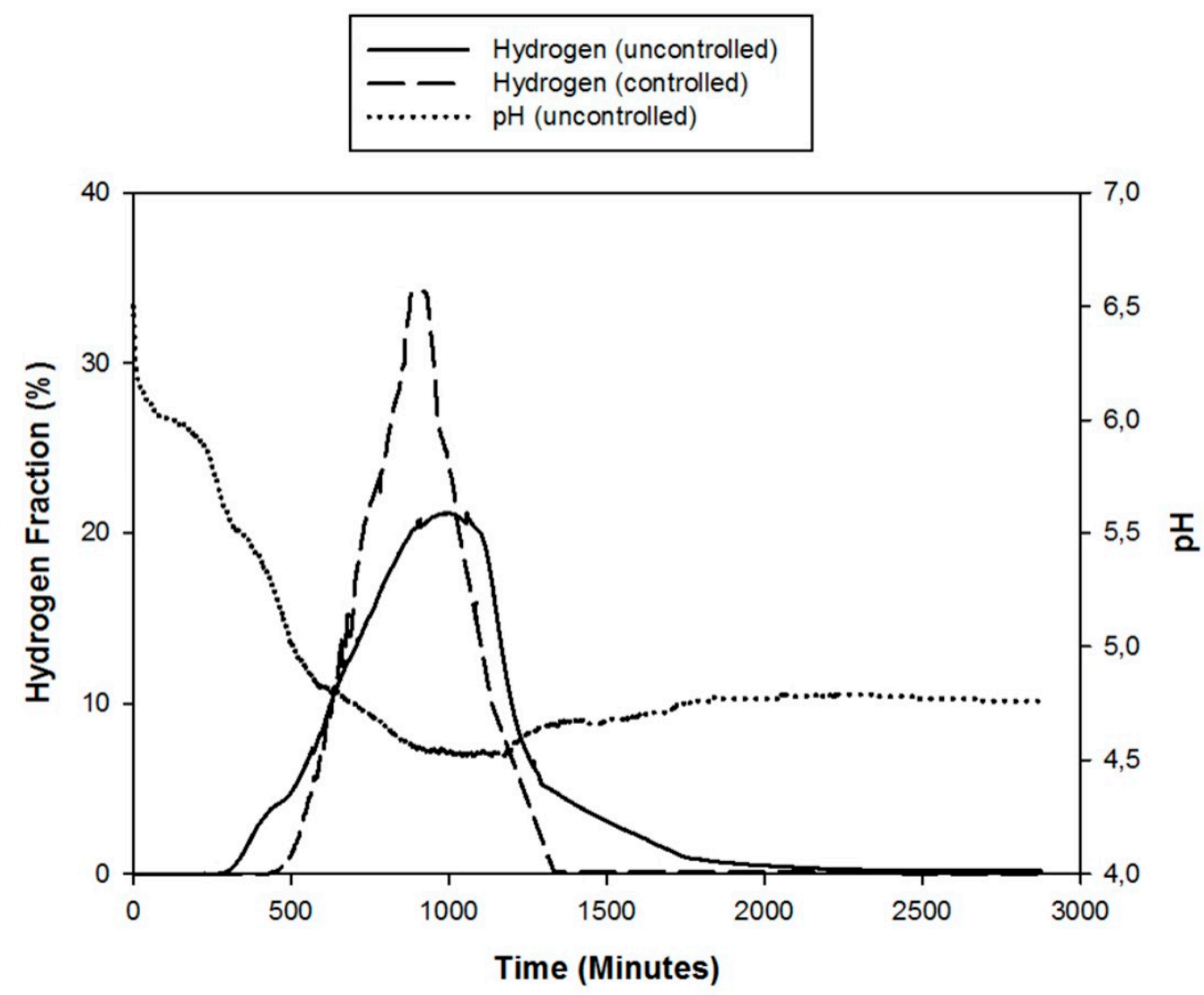

Figure 3: A comparative evolution of hydrogen fraction and $\mathrm{pH}$ under regulated $(\mathrm{pH} 6.5)$ and non-regulated pH conditions using immobilized cells

Although the immobilized cell system resulted in a lower peak hydrogen fraction compared to suspended cells, the extended peak production phase implies that cell immobilization, even under non-regulated conditions could enhance biohydrogen production. The lower hydrogen fraction obtained with alginate immobilized cells in flask culture may be attributed to vigorous gas production in the flask cultures which reduces the density of the beads, causing them to 
float and be clustered at the surface of the culture medium at the conical top of the flask (Figure 4), thus reducing the availability of nutrients [16]. These observations suggest that a novel reactor configuration may be appropriate for biohydrogen investigation with alginate immobilized cells at laboratory scale. The slope of the $\mathrm{pH}$ evolution curves for both immobilized and suspended cells were 0.0003 and 0.0006 , respectively. This shows that the rate of $\mathrm{pH}$ change was slower for immobilized cells compared to suspended cells.

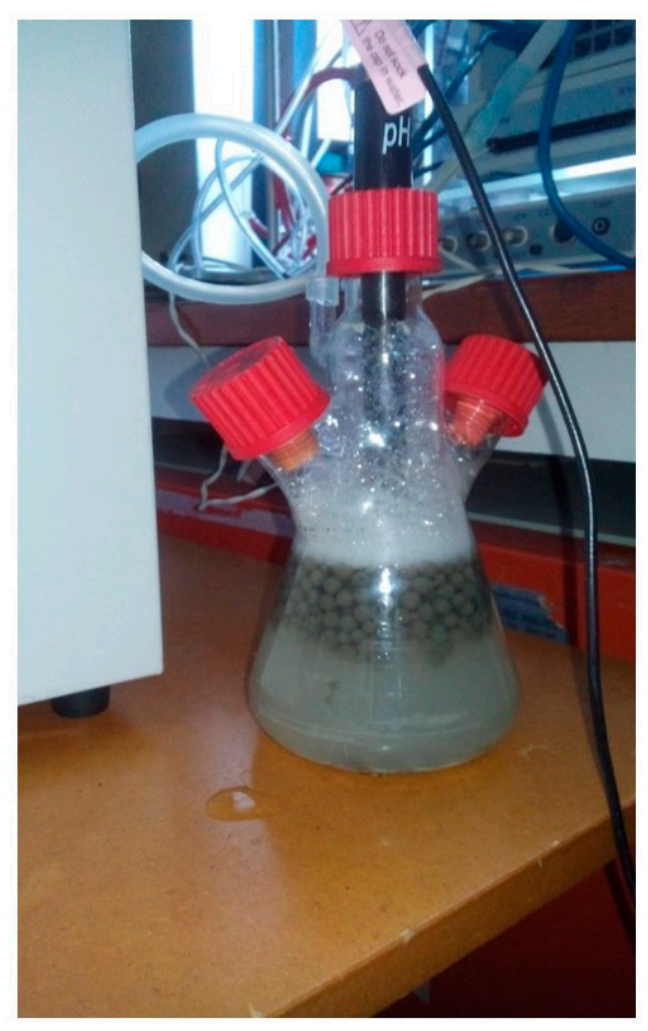

Figure 4: Reactor flask with sodium-alginate immobilized cells at exponential hydrogen production showing bead flocculation and excessive foam production at the neck of the

\section{flask}

\subsubsection{Effect of non-regulated $p H$ on substrate degradation using immobilized cells}

The glucose concentration decreased from an initial concentration of $10 \mathrm{~g} / \mathrm{L}$ to $7.2 \mathrm{~g} / \mathrm{L}$ at exponential phase and then to $4.9 \mathrm{~g} / \mathrm{L}$ at peak hydrogen production. The final residual glucose 
concentration was $0 \mathrm{~g} / \mathrm{L}$, revealing a complete utilization of carbon substrate of the medium. This suggested that the decline in hydrogen production may be anchored to the depletion of glucose or $\mathrm{pH}$ limit threshold as discussed above. Correlation studies showed a strong relationship between $\mathrm{pH}$ change and hydrogen production. Strong correlation values were observed between the hydrogen evolution and $\mathrm{pH}$ trends at lag phase, exponential phase as well as the decline phase with correlation coefficients of $0.94,0.93$ and 0.92 , respectively.

\subsubsection{Biohydrogen production and substrate degradation profiles under $\mathrm{pH}$ regulated} conditions in immobilized cells culture.

Figure 3 also shows the evolution of biohydrogen under regulated $\mathrm{pH}$ conditions using immobilized cells. A lag phase of 8 hours can be observed. After 8 hours, a rapid upsurge in the hydrogen production with a peak hydrogen fraction of 35\% was observed at 15 hours. The peak hydrogen production phase lasted up to 35 minutes. This was followed by a gradual reduction in the production of hydrogen which may be attributed to nutrient depletion within the fermentation medium. To assess this possibility, glucose degradation was monitored at regular intervals. Glucose was added to the initial culture medium at a concentration of $10 \mathrm{~g} / \mathrm{L}$ under regulated $\mathrm{pH}$ conditions. During the exponential phase (5-15 hours), the glucose concentration in the fermentation medium decreased from 10 to $8.1 \mathrm{~g} / \mathrm{L}$. At peak hydrogen production the measured glucose concentration was $0 \mathrm{~g} / \mathrm{L}$. This suggested that cell immobilization enabled a complete utilization of the substrate and thus hydrogen production ceased due to the depletion of substrate in the fermentation system. The lower peak hydrogen fraction observed in the study with immobilized cells culture systems can be accounted by bead flocculation, and also an inefficient mixing [16], however, these systems still presented the advantage of complete substrate degradation. 


\subsection{Microbial analysis}

Minton and Clarke [36] stipulated that hydrogen production occurred during the exponential growth phase of Clostridia. Scanning electron microscopy (Figure 5 and 6) showed a microbial population consisting predominantly of rod-shaped cells which suggested the presence of hydrogen producing Clostridia.
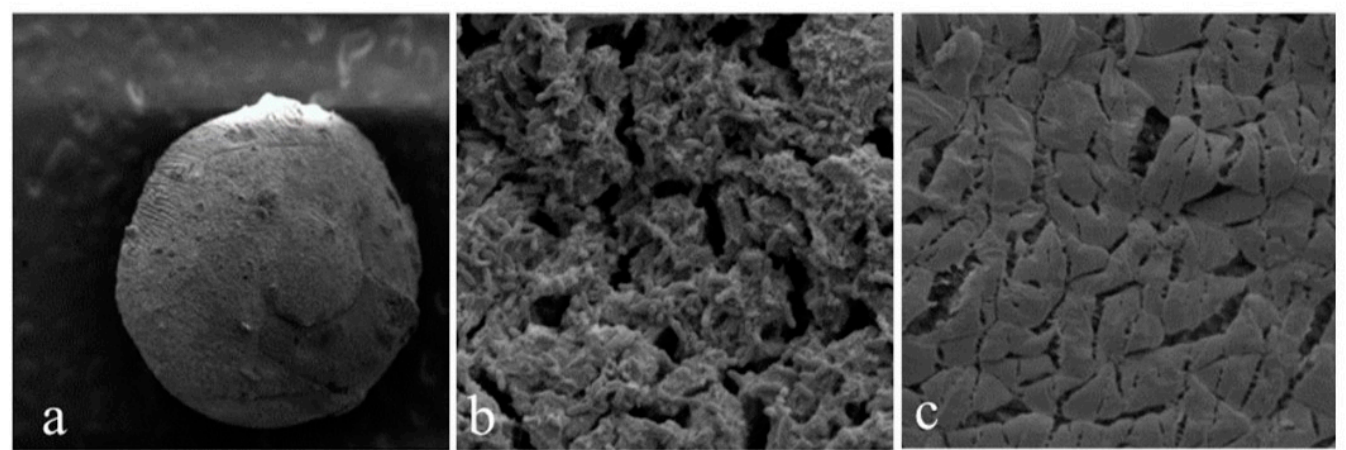

Figure 5: Scanning electron microscopy (SEM) images of unprocessed alginate bead (a), bead ran under regulated $\mathrm{pH}$ conditions (b) and bead ran under non-regulated $\mathrm{pH}$ conditions (c)

The alginate beads used as an entrapment matrix are represented in figure $5 \mathrm{a}, \mathrm{b}$ and $\mathrm{c}$. Figure $5 \mathrm{~b}$ shows a dense, mixed microbial population which occurs on the surface of the bead ran under regulated $\mathrm{pH}$ conditions. However, figure $5 \mathrm{c}$ shows the surface of a bead ran under nonregulated $\mathrm{pH}$ conditions. The surface of this bead appears to be smooth with no visible growth on the surface. This observation suggests that the change in $\mathrm{pH}$ of the media surrounding the outer surface may have resulted in the microbial population being washed off the surface of the bead. 

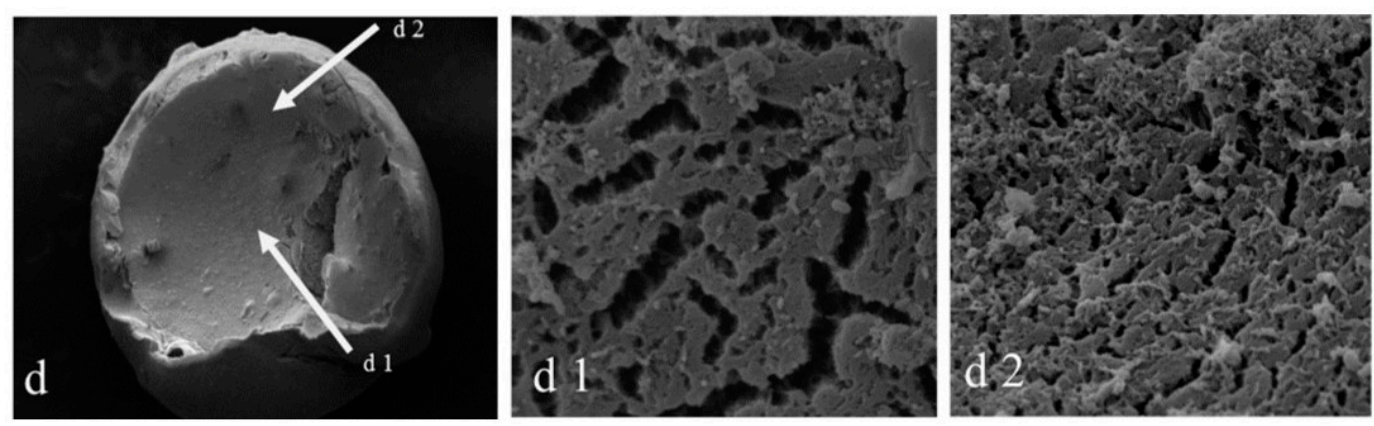

\section{Figure 6: Scanning electron microscopy (SEM) images of cross sectional bead under} non-regulated pH (d), the magnified center of the bead (d1) and the top edge of the bead (d2)

The cross sectional area of the beads was observed under scanning electron microscopy (Figure 6). This analysis showed a mixed microbial population present with an irregular spatial distribution. More microbial cells were visible toward the outer edges of the bead (Figure d2) compared to the center of the bead (Figure d1). This observation raises the possibilities of gradients (nutrients or $\mathrm{pH}$ ) across the bead, with a greater concentration of nutrients at the outer edges of the bead which gradually decreased toward the center of the bead. The granular activated carbon (GAC) was added to the alginate-sludge mixture to increase bead porosity and enhance the transfer of nutrients across the bead. Mass and heat transfer across the beads could be potential limitations for the use of immobilized cell systems, thus an investigation of the optimum GAC content could enhance the efficiency of the culture modes.

Although, the findings showed that the use of suspended cells generated a higher hydrogen fraction as compared to immobilized cells, these systems showed a premature process termination with an incomplete substrate utilization when the medium $\mathrm{pH}$ was not regulated. $\mathrm{pH}$ regulation in suspended cell systems increased substrate degradation thus resulting in a 
higher hydrogen fraction. Immobilized cell systems on the other hand allowed for complete substrate degradation even under non-regulated $\mathrm{pH}$ conditions. Additionally, this system showed a better buffering capacity under non-regulated $\mathrm{pH}$ conditions as the rate of change in $\mathrm{pH}$ was slower as compared to the suspended cell system. However, the hydrogen fraction observed with immobilized cells was lower compared to hydrogen production with suspended cells due to cell flocculation that limited the release of gas out of the bead matrices. Thus reactor configuration may improve hydrogen production for these culture systems with alginate immobilized cells.

\section{Conclusion}

The regulation of culture medium $\mathrm{pH}$ increased the hydrogen fraction and glucose degradation for both suspended and immobilized cells. pH drift was more pronounced with suspended systems compared to immobilized systems which displayed relative stability, suggesting that cell immobilization may have improved the buffering capacity of the system. However, biohydrogen research in flask systems was limited by gas entrapment within the immobilization-matrix causing flocculation of the beads and reducing cell metabolism. These findings highlight the sensitivity of dark-fermentation to $\mathrm{pH}$ oscillations in flask experimentation and the relative $\mathrm{pH}$ stability in alginate-immobilized culture systems, making them suitable for experimentation when conventional feedback $\mathrm{pH}$ control loops are difficult or expensive to implement.

\section{ACKNOWLEDGEMENTS}

This work was supported by the under grant, National Research Foundation (NRF). 


\section{REFERENCES}

1. Gupta, S.K.; Kumari, S.; Reddy, K; Bux, E. Trends in biohydrogen production: Major challenges and state of the art development. Environ. Technol, 2013, 34 (13-16), 16531670

2. Liu, I.C.; Whang, L.M.; Ren, W.J.; Lin, P.Y. The effect of $\mathrm{pH}$ on the production of biohydrogen by Clostridia: Thermodynamics and metabolic considerations. Int. J. Hydrogen Energy, 2011, 36, 439-449

3. Van Ginkel, S.; Sung, S.; Lay, J.J. Biohydrogen production as a function of $\mathrm{pH}$ and substrate concentration. Environ. Sci. Technol, 2001, 35, 4726-4730

4. Kapdan, I.K.; Kargi, F. Biohydrogen production from waste materials. Enzyme. Microb. Technol, 2006, 38, 569-582

5. Perera, K.R.J.; Ketheesan, B.; Gadhamshetty, V.; Nirmalakhandan, N. Fermentative biohydrogen production: evaluation of net energy gain. Int. J. Hydrogen Energy, 2010, 35, 12224-12233

6. Ramachandran, R.; Raghu, K.M. An overview of industrial uses of hydrogen. Int. J. Hydrogen Energy, 1998, 7, 593-598

7. Basak, N.; Das, D. Microbial biohydrogen production by Rhodobacter sphaeroides O.I.001 in photobioreactor. Proceedings of World Congress on Eng. and Computer Sci., San Francisco, USA 2007

8. Wongthanate, J.; Chinnacotpong, K.; Khumpong, M. Impacts of $\mathrm{pH}$, temperature and ,pretreatment method on biohydrogen production from organic wastes by sewage microflora. International J. Energ. Environ. Eng, 2014, 5 (6) doi:10.1186/2251-6832-5-6

9. Lavine, D.B.; Chahine, R. Challenges for renewable hydrogen production from biomass. Int. J. Hydrogen Energy, 2010, 35, 4962-4969

10. Raghavulu, S.V.; Venkata-Mohan, S.; Goud, K.R.; Sarma, P.N. Effect of anodic pH microenvironment on microbial fuel cell performance in concurrence with aerated and ferricyanide catholytes. Electrochem. Commun, 2009, 11, 371-375

11. Kawagoshi, Y.; Hino, N.; Fujimoto, A.; Nakao, M.; Fujita, Y.; Sugimura, S.; Furukawa, K. Effect of inoculum conditioning on hydrogen fermentation and $\mathrm{pH}$ effect on bacterial community relevant to hydrogen production. J. Biosci. Bioeng, 2005, 100 (5), 524-530

12. Harms, P.; Kostov, Y.; Rao, G. Bioprocess monitoring. Curr. Opin. Biotechnol, 2002, 13, 124-127

13. Liu, B.F.; Ren, G.J.; Ding, J.; Guo, W.Q.; Xing, D.F. Enhanced biohydrogen production by the combination of dark and photo-fermentation in batch culture. Bioresour. Technol, 2010, 101, 5325-5329

14. Khanal, S.K.; Chen, W.S.; Li, L.; Sung, S. Biological hydrogen production: Effects of pH and intermediate products. Int. J. Hydrogen Energy, 2004, 29 (11), 1123-1131

15. Chu, C.Y.; Tung, L.; Lin, C.Y. Effect of substrate concentration and $\mathrm{pH}$ on biohydrogen production kinetics from industry wastewater by mixed culture. Int. J. Hydrogen Energy, 2013, 38, 15849-15855 
16. Wu, S.Y.; Lin, C.N.; Chang, J.S.; Lee, K.S.; Lin, P.J. Microbial Hydrogen production with immobilized sewage sludge. Biotechnology processes, 2002, 18(5), 921-926

17. Zhu, H.; Suruki, T.; Tsygankov, A.A.; Asada, Y.; Miyake J. Hydrogen production from tofu wastewater by Rhodobacteria sphaeroids immobilized in agar gels. Int. J. of $\mathrm{H}_{2}$ energy, 1999, 24, 305-310

18. Kumar, N.; Das, D. Continuous hydrogen production by immobilized Enterobacter cloacae IIT-BT08 using lignocellulosic materials as solid matrices. Enzyme Microb. Technol, 2001, 29, 280-287

19. Klöckner, W.; Diederichs, S.; Büchs, J. Orbitally shaken single-use bioreactors. Advanced Biochemical Engineering and Biotechnology, 2014, 138, 45-60

20. Klöckner, W.; Büchs, J. Advances in shaking technologies. Trends in Biotech. 2012, 30 (6), 307-314

21. Garcia-Ochoa, F.; Gomez, E. Bioreactor scale up and oxygen transfer rate in microbial bioprocesses: An overview. Biotech. Adv, 2009, 27,153-176

22. Faloye, F.D.; Guegium-Kana, E.B.; Schmidt, S. Optimization of hybrid inoculum development techniques for biohydrogen production and preliminary scale up. Int. J. Hydrogen Energy, 2013, 38 (27), 11765-11773

23. Gueguim Kana, E.B.; Schmidt, S.; Azanfack Kenfack, R.H. A web enabled software for real-time biogas fermentation monitoring - Assessment of dark fermentations for correlations between medium conductivity and biohydrogen evolution. Int. J. Hydrogen Energy, 2013, 38 (25), 10235-10244

24. O'Sullivan, E.; Condon, S. Relationship between acid tolerance, cytoplasmic $\mathrm{pH}$ and ATP and $\mathrm{H}^{+}$- ATPase levels in chemostat cultures of Lactococcus lactis. Appl. Environ. Microbiol. 1999, 65 (6), 2287-2293

25. Wang, J.; Wan, W. 2008 Effect of temperature on fermentative hydrogen production by mixed cultures. Int. J. Hydrogen Energy, 2008, 33 (20), 5392-5397

26. Hallenbeck, P.C. Fundamentals of fermentative production of hydrogen. Wat. Sci. Tech, 2005, 52, 21-29

27. Tang, G.L.; Huang, J.; Sun, Z.J.; Tang, Q.Q.; Yan, C.H.; Liu, G.Q. Biohydrogen production from cattle waste water by enriched anaerobic mixed consortia: Influence of fermentation temperature and pH. J. Biosci. Bioeng. 2008, 106 (1), 80-87

28. Zhao, C.; Lu, W.; Wang, H.; Pan X. Simultaneous hydrogen and ethanol production from a mixture of glucose and xylose using extreme thermophiles: Effect of substrate and $\mathrm{pH}$. Int. J. Hydrogen Energy, 2013, 38, 9701-9706

29. Venkata, MS.; Babu, V.L.; Sarma, P.N. Effects of various pretreatment methods on anaerobic mixed microflora to enhance biohydrogen production utilising dairy wastewater as substrate. Bioresour. Tech. 2008; 99 (1), 59-67

30. Even, S.; Lindley, N.D.; Loubiere, P.; Cocaign-Bousquet, M. Dynamic response of catabolic pathways to auto-acidification in Lactobacillus lactis: Transcript profiling and stability in relation to metabolic and energetic constraints. Mol. Microbiol. 2002, 45, 1143 1152 
31. Grady Jr., C.P.L.; Daigger, G.T.; Lim, H.C. Biological waste water treatment, $2^{\text {nd }}$ ed., Chapter 13.91999

32. Li, Y.; Zhu, J.; Wu, X.; Miller, C.; Wang, L. The effect of $\mathrm{pH}$ on the continuous biohydrogen production from swine waste water supplemented with glucose. Appl Biochem Biotech, 2010, 162, 1286-1296

33. Niel, E.W.J.; Classen, P.A.M.; Stams, A.J.M. Substrate and product inhibition of hydrogen production by extreme thermophile Caldicellulosiruptor saccharolyticus. Biotechnol. Bioeng. 2003, 81, $255-262$

34. Zheng, X.J.; Yu, H.,Q. Inhibitory effects of butyrate on biological hydrogen production with mixed anaerobic cultures. J Environ Manag, 2005, 74(1), 65-70

35. Fang, H.H.P.; Lui, H. Effects of $\mathrm{pH}$ on hydrogen production from glucose by mixed culture. Bioresour. Technol, 2002, 82(1), 87

36. Minton, N.P.; Clarke, D.J. Biotechnology Handbooks. Vol 3: Clostridia. New York: Plenum Press 1989

(C) 2016 by the authors; licensee Preprints, Basel, Switzerland. This article is an open access article distributed under the terms and conditions of the Creative Commons by Attribution (CC-BY) license (http://creativecommons.org/licenses/by/4.0/). 